\title{
Using Breach Experiments to Explore Price Setting in Everyday Economic Locations
}

\author{
Daniel Neyland, Marta Gasparin, Lucia Siu
}

\begin{abstract}
This paper draws inspiration from the breach experiments of Garfinkel as a basis for exploring the naturally occurring order of price setting in locations without an institutionalised single price rule. We organised two experiments (at a flea market in Copenhagen and boot sale in Oxford) to study price setting. The findings suggest that members of price setting interactions accountably, demonstrably and reflexively accomplish a regularly repeated order to price setting through constitutive expectancies and the congruence of relevances that are made available within interactions. In conclusion we suggest that our experiments proved to have analytic utility in bringing gently structured comparisons to the fore. The experiments provided us with the opportunity to engage with the basis for price setting in different everyday economic locations and we felt that this was the opening to a mode of research that has future potential.
\end{abstract}

Key words: market; price; experiment; breach; mundane; Garfinkel

Our paper opens in Beijing in autumn, 2005, and Lucia is shopping for a cardigan. She knows about the notoriety of Silk Street market traders, with online forums warning: "Be prepared to be ripped off" and "This is a terrible place to be," along with: "Lots of fun, good quality fakes." With rapid economic expansion and changes in the local area signalled by the arrival of embassies and expatriates, Silk

Daniel Neyland, (corresponding author), Sociology Department, Goldsmiths,

University of London, d.neyland@gold.ac.uk

Marta Gasparin, School of Business, University of Leicester, mg352@le.ac.uk

LuciaSiu,lucia.siu@gmail.com

(C) 2019 Authors

LiU Electronic Press, DOI 10.3384/VS. 2001-5992.19615

http://valuationstudies.liu.se 
Street has become an amalgam of conflicting pricing rules. Should prices be determined by local material costs, or the consumption power of willing foreign visitors? In the case of alleged counterfeit goods, price negotiations can encompass anything between a no-frill local item and the original designer brand product. The place is filled with a competitive atmosphere: local traders grasp every opportunity to strike for aggressive profits, while many tourists enjoy bargaining more as an exotic sporting experience than for the final items they purchase.

The waters are so murky that even locals have lost a clear sense of what would count as a "good" price. As a visitor from Hong Kong, Lucia is expecting a long and winding negotiation process. She expects the trader to offer an initial price somewhere in the region of four to 12 times the price she will eventually pay. She expects the trader to enter into one of the common routines for justifying price. She has been taken by a trader to a quiet corner to say: "I am only offering this special price to you because you're a fellow Chinese, don't tell other customers;" but other customers are likely to experience exactly the same thing, with "fellow Chinese" being substituted by "nice person", "handsome guy", "pretty girl", or "a smart foreigner". Other traders are imploring: "Good quality! Look, good quality!" or "If you buy five items, I can lower the total price to 250 ," or "50 is impossible! Take pity on us, we have to live." At the same time, would-be shoppers respond by suggesting: "A friend of mine bought the same item in Hongqiao market [opposite Beijing Zoo] for 30. You are selling it far too expensive here." Lucia has noticed a shopper turning her purse inside out: "Sixty is all I have here. Take it or we have no business."

Lucia has found a cardigan she likes, but how should she negotiate the price? By making a low offer? By feigning non-interest? By walking away in the hope of getting a lower offer? But when should she walk and how far and how fast? An expatriate shares with Lucia the rule of walking away: "I have a golden yardstick of when you have hit a fair price. If you try to walk out and the salespersons no longer try to chase, you know you have hit the fair price."

Setting a price in Beijing's Silk Street market seems to require navigation of this elaborate combination of words, goods, amounts, walking and not walking. In this setting economic lives are made and maintained through prices. Price setting seems to involve a regularly repeated order that includes pointing up things to hand (quality, handsomeness, an empty purse) and indexing notable others (other markets, other inferior goods or customers) to create contrast structures (pointing to a lower price at another market, implying a special deal). Presence (being in a position to point up a feature) and absence (walking away) seem central to setting the price, as does timing (when to walk, when to chase, when to buy). The order of price setting seems to be naturally occurring at least to the extent that there 
is no one participant in full control of the outcome. Yet despite this apparent regularity of features through which prices are set, the one thing that is not constant is the price. One customer may pay anything up to 12 times the price of another customer for the same cardigan.

How can we account for the specific intricacies of the naturally occurring order of price setting in locations like Silk Street without an institutionalised single price rule? ${ }^{1}$ There is a broad array of theorizing of price 2 in relation to, for example, marketing (Kotler 1972; Pine and Gilmore 1999; Zeithaml 1988), and market shaping (Giesler 2008, 2012; Humphreys 2010; Scaraboto and Fischer 2013), through sociology (Simmel 2004; Veblen 1899; Csikszentmihalyi and Halton 1981; Bourdieu 1984) and economic sociology (Fourcade 2010; Zelizer 1981; Aspers 2011). These studies undoubtedly raise interesting questions of worth (Stark 2009), sustainability (Finch et al. 2016) and taste (Hennion 2004) among many other things. However, as Beckert (2011) suggests: "In many studies on markets coming out of economic sociology, prices are not mentioned at all. This is a profound shortcoming" (2011: 3). And many of these studies tend to utilise historical or generalised examples for their analysis or draw on second order accounts of prices through, for example, blogs (Scaraboto and Fischer 2013).

For our purposes, these studies also tend to engage with settings that depend upon the institutionalisation of a single price rule (Cochoy 2008; Cochoy and Grandclément 2005), even if the settings themselves are very different. In order to develop a focus on the regularly repeated, naturally occurring order of price setting in locations without fixed prices, there are three broad groups of relevant work that can provide useful starting points. First, there is economic experimentation that engages with the prices paid for goods (Miller 2002; Smith 1962, 2000; Tversky and Kahneman 1986). These experiments are interesting insofar as they hypothesise the constituent features of price setting. However, the focus then tends to be on transforming these hypotheses into variables to be manipulated and controlled, opening up critiques that the experimenters might be imposing important features of price setting (for critical engagement with economic experiments, see Guala 2008; Muniesa and Callon 2008; MacKenzie 2002). To study naturally occurring order in price setting might require a different kind of intervention.

Second, there is up-close, ethnographic work on stock exchanges (on stock markets and arbitrage pricing, see Beunza et al. (2006); on closing prices, see Muniesa (2007); or pricing in trading pits, see

1 The term institutionalised single price rule is derived from Garfinkel's (1967) work, as we will go on to explore.

2 This paper is not designed as a literature review on prices and the references included here are just entry points to guide readers toward relevant studies. 
Caliskan (2007)). These studies are interesting for our purposes in that, taken together, they provide a comparison of the order of pricing from the rehearsal price to the market price of cotton in the Izmir Mercantile Exchange (Cailskan 2007) in contrast to, for example, algorithmically derived prices in Paris (Muniesa 2014). However, they also point towards a requirement for precision in drawing up the parameters of our research: locations like Silk Street and the naturally occurring order of price setting activities that takes place therein are quite distinct from trading pits. When we consider places like Silk Street we are expressing a preference for studying the naturally occurring order of price setting in locations without an institutionalised single price rule where anyone can take part, no training is required and no special rules of access are imposed-and yet an order is still perceivable. These settings provide something like a hardest possible case for an order of price setting to endure: stripped of the kind of institutional explanations that a social scientist might be tempted to fall back on in accounting for the order of price setting (rules, regulations, laws, access requirements, training, uniforms, algorithms, technologies, devices), how can we account for price setting? We will refer to these locations without a strong institutionalised backdrop or access control as everyday economic locations.

A third corpus of work is similarly useful. This is comprised of ethnographies of situations where face to face interaction around price is permitted and expected as a feature of the order of the location wherein prices are set. Auctions, flea markets and car boot sales provide the locations for exploring the social construction of value (Smith 1990) or what it means to possess an object (Gregson et al. 2013; Gregson and Rose 2000 Gregson and Crewe 1997). These studies are useful insofar as they point to the varied characteristics of different locations not characterised by a single price rule and draw our attention to various extrapolations we can make from such studies (regarding value or possession for example). But these studies also leave us wanting to know more about the distinct order of price setting in these locations; just how do participants with no apparent shared background, no prior knowledge of each other, no training and no specific access requirements, come together and regularly reproduce an order to price setting that is somehow recognisably characteristic of that setting?

Both studies of stock markets and flea markets, in common with other ethnographic work, depend to a large extent upon the visual, material and audible cues made apparent within locations by members of those locations to make sense of the order of pricing. In a similar manner to our opening Silk Street example, what appears to be taking place provides the grounds for analysis. But what if each setting is characterised by a large number of unwritten, unspoken forms of 
order-what Garfinkel (1963) termed constitutive expectancies? Constitutive expectancies encompass the expectation that one member of an interaction has of themselves and their role in an interaction and the expectancies they have of other members of the interaction and the expectation that other members have of themselves and the other members of the interaction. These are constitutive in that members of the interaction point to these expectancies by, for example taking a turn in a conversation and expecting another member of the interaction to take the next turn. Such expectancies are constitutive also because they do things; it is their "operativeness" that "serves as an important condition of stable features of concerted actions" (Garfinkel 1963: 200). At moments of breakdown in interactions, repairs are often based on explicitly stating the expectations that underpinned the interaction and the order that such expectations anticipated. These expectancies are not, though, written rules or necessarily defined at the outset of an interaction. In this way, the "constitutive order" (Garfinkel 1963: 196) of an interaction unfolds as each participant in the interaction offers an account that demonstrably makes available a sense of preceding turns and sets expectations regarding proceeding turns in the interaction. Price setting, as we will explore, provides a location in which such constitutive expectations and the orders to which they give shape can be explored. Our suggestion is that we need a method to bring these constitutive expectancies to the fore in order to engage with the orders of price setting in locations without an institutionalised single price rule. This is where the paper will begin.

\section{Ethnomethods of price setting ${ }^{3}$}

Ethnomethodologists are interested in the methods used by members of an interaction to constitute the sense of the interaction-the orderin which they are members. Order is accomplished through accountable, demonstrable interactions that progressively realise the sense of the interaction and sanction the competence of other members to take part in the successive unfolding of the order of the interaction. The order is naturally occurring in the sense that it is a product of the interaction. Sanctioning happens by displaying expectations for others to recognise through turns in the interaction, through calls for other participants to display their competence in responding to and calling forth further expectations and building what Garfinkel termed the "congruency of relevances"-that what is made accountably, demonstrably relevant by one participant is recognised by and shared

3 The paper will specifically focus on the work of Garfinkel and subsequent analysis of his work, rather than other ethnomethodological developments in, for example, conversation analysis or human computer interaction that are less directly relevant to the focus of this paper. 
with (or congruent to) the other participants. This builds into an ongoing, naturally occurring social order insofar as participants in interactions manage to adopt a relation of undoubted correspondence between the appearance and reality of the interaction as it unfolds. 4 Relations of doubtful correspondence are negatively sanctioned. 5 Negative sanctioning can take place through breakdowns in interaction, questions or strategies of repair to get interactions back on track. The outcome of interactions is an interchangeability of viewpoints achieved through the congruence of relevances; that each member has accomplished a sense of the scene that is in-principle interchangeable among participants. They are each aware and assume the others are aware of the sense that has been achieved.

This may go some way to establishing the grounds for making a particular kind of sense of price setting in everyday economic locations without a single price rule. We would need to get close to price setting activities in locations like Silk Street and study the demonstrable and accountable accomplishment by participants of the congruence of relevances, and any subsequent sanctions. We might also need a method to make constitutive expectancies available for analysis. Furthermore, we would need to navigate what ethnomethodologists suggest are three recurring features of constitutive expectancies and the order of interactions in which they are involved: reflexivity, indexicality and inconcludability. We will start to make sense of price setting by turning attention to these three features.

For Garfinkel there could be no study of social order without reflexivity. This is not a general sense of reflexivity as a reflection on the nature of things or as an academic virtue in which scholars might reflect on their own research efforts (Lynch 2000). Instead, reflexivity is the means through which participants in an interaction constitute the sense of that interaction by continuously bringing its order into being-by offering turns in a conversation, for example, that demonstrably account for previous turns, are hearable as a sensible part of the interaction by other participants and can be used to provide a further accountable turn in the interaction. Reflexivity is thus what makes order study-able by continually making that order available. Or as Garfinkel suggests: "By permitting us to locate and examine their occurrence the reflexivity of that phenomenon establishes their

\footnotetext{
${ }^{4}$ This is Garfinkel's radical notion of what constitutes trust-that the conditions for undoubted correspondence are achieved and shared by members of the interaction.

${ }^{5}$ And this amounts to a situation of distrust in that the necessity and motivation of the other participants in participating in the interaction is required to be called to account when the correspondence of what is taking place and what appears to be taking place, breaks down.
} 
study" (1967: vii). 6 In order to make sense of the order of price setting, then, we social scientists need to learn "how members' actual, ordinary activities consist of methods to make practical actions, practical circumstances ... analysable" (1967: viii).

This constitutive approach to reflexivity is inseparable from the indexicality of such matters as turns in a conversation or other types of account that interactionally accomplish the sense of a scene. For Garfinkel there is no context that is analytically separate from the locations in which interactions take place (Livingston 2006). Instead, interactions provide the location in which sense of the interaction is reflexively accomplished by indexing or pointing towards or making accountably and demonstrably available any sense of context that is required for the interaction to sensibly continue. As Garfinkel's study of suicide suggests, "Organizationally, the Suicide Prevention Centre consists of practical procedures for accomplishing the rational accountability of suicidal deaths as recognizable features of the settings in which that accountability occurs" (1967: 9). Society is indexed through the dead body, its trappings, surroundings and memorabilia. Garfinkel draws on Mannheim's documentary method of interpretation here to explore how the treatment of the actual appearance of the dead body acts as the document of (or indexes or points towards) its underlying pattern or meaning. ${ }^{7}$ For price setting this would require that the interactional turns of, for example Silk Street negotiations were analysed through their indexical expressions. We have already seen some of this in our opening example, with other shoppers, locations and prices indexed as the basis for giving meaning to the current price being offered, resisted or paid.

For Garfinkel, expressions are not only indexical (pointing to things that then become part of the interaction) and reflexive (with ongoing constitution of the sense of the scene accomplished and made available within the scene), but also "inconcludable". That is, any account of any matter in any interaction is open to further question as to the precise nature of its purpose, sense or meaning. Even coroners' certifications of death as suicide, for example, are only warranted for all practical purposes. Garfinkel suggests that in certifying death any matter to hand not only will do, but does. In this way, whatever the members of the Suicide Prevention Centre are faced with must serve as the basis for reading the remains of a body to see how society could have operated to produce what the inquirer in the end has. Although in many interactions members reflexively constitute the importance of

\footnotetext{
${ }^{6}$ From here it should not be assumed that any sense of a scene is permissible. Instead accounts are sanctioned within interactions.

7 This is a radical extension of linguists' use of indexical to refer to a fixed set of terms whose meaning is tied to their use in a conversation. For Garfinkel, all accounts are indexical.
} 
and index the need to produce an account that can withstand counter claims or contrary accounts, members also often apply an etcetera clause in making sense of others' accounts. Such a clause enables a participant in an interaction to simultaneously pay recognition to the principle that further questions could always be asked, at the same time as they get on with the matters to hand. An etcetera clause enables for all practical purposes this account to pass as adequate for the current purpose.

For studying price setting this establishes some notable challenges. To make sense of price setting in everyday economic locations without an institutionalised single price rule appears to require a means to make available to the analyst constitutive expectancies, the congruence of relevances, reflexivity, indexicality and inconcludability, the ways in which accounts are produced to resist counterclaims and any etcetera clause deployed. However, Garfinkel provided a seemingly straightforward means to make the naturally occurring order of interactions available to the analyst:

In accounting for the persistence and continuity of the features of concerted actions, sociologists commonly select some set of stable features of an organisation of activities and ask for the variables that contribute to their stability. An alternative procedure would appear to be more economical: to start with a system with stable features and ask what can be done to make for trouble. The operations that one would have to perform in order to produce and sustain anomic features of perceived environments and disorganised interaction should tell us something about how social structures are ordinarily and routinely being maintained. (1963: 187)

This was the rationale behind Garfinkel's $(1963,1967)$ breach experiments, conceived as the basis for analytic engagement with the persistent, naturally occurring order of interactions characterised by accountability, reflexivity, indexicality and inconcludability. The experiments included Garfinkel asking students to return home and act as if they were lodgers in their own homes rather than members of the family. The breaches and repairs (or attempted repairs) offered opportunities to consider the order of these forms of interaction. The constitutive expectancies that students were to act in particular ways as members of a family which involved sitting in certain ways at the dinner table, addressing family members using certain terms, talking about particular subjects and so on, were made available through the moment of breach.

In these experiments, the breach thus places questions by constitutive expectancies (such as the relationship of undoubted correspondence between a matter and what it appears to be) that then need to be accounted for by participants in the interaction. The kind of explanations that need to be accounted for can include fundamental matters, including for example: that something is said in order to be intelligible within a setting and in the process constitute the sense of 
the setting; that expressions index a context through which the expressions can be made to make reflexive sense; that although inprinciple inconcludable such matters as etcetera clauses will be utilised to bring otherwise endless questions to a halt. 8

The breaches thus gave a practical shape to the documentary method of interpretation. In one experiment, students asked advice from a person they were told was a counsellor, who was in fact reading out yes or no answers to students' questions according to a pre-prepared script. Students made sense of the answers as answers to their questions (rather than as a randomly assigned 'yes' or 'no' read out from a script), but they did so in a specific way. The answers given by counsellors were understood as pointing to an underlying meaning by the students. These were not just random yes or no answers, but could be made to make sense within this setting as a solution to the question they had posed. Students thus gave warrant to the advice by invoking constitutive expectancies to which they assumed themselves and the experimenter were bound as members of the same interaction - they indexed a congruence of relevances. According to Garfinkel, the counsellor's responses were granted the warrant of being sufficient by students through constitutive expectancies that what was true to the scene was what could be made normal. By making the counsellors' answers normal to the scene, they were warranted true. Hence we might explore the moral warrants accomplished in price setting interactions through which what counts as a normal price and normal method of price setting is accomplished.

For our purposes, the most salient of the breach experiments was Garfinkel's efforts to get his students to bargain for standard priced merchandise in locations with an institutionalised single price rule. According to Garfinkel's (1967) unfortunately brief reporting of the results, this experiment revealed details on the constitutive expectancy of the institutionalised single price rule. Sixty-eight students were required to enter into a single interaction and offer less than $\$ 2$ for a $\$ 2$ item in a shop with fixed prices. A further 67 students were then asked to carry out six trials, three for items under $\$ 2$ and three for over $\$ 50$ also in shops with fixed prices. Garfinkel reports that students in the second group found it easier over time to enter into bargaining over fixed prices. It was breaching the constitutive expectancy the first time that was challenging and it was the trouble caused by this initial breach that occupied much of students' descriptions of the experiment.

8 Indeed one breach experiment involved students continually asking further questions based on answers given in response to previous questions, demonstrating the otherwise pervasiveness of etcetera clauses; that answers are not only passable, but are made to pass. 


\section{Valuation Studies}

Drawing these ideas together in order to bring to bear analytic attention upon the precise detail of price setting in everyday economic locations without an institutionalised single price rule required that we devised our own breach experiments. Given that the breach experiments raised ethical questions with participants only made aware of the breach after it had taken place, potentially causing anxiety to participants, we looked to develop a form of experiment that could address these ethical concerns. Our experiments included a Danish flea market and a UK car boot sale-everyday economic locations without a single price rule. We took part as sellers and omitted prices from any of our items. When approached by potential customers we then informed them (as far as possible) ${ }^{9}$ of the experiment and sought to encourage participants to account for the prices they assigned to goods. Prior to the experiments, we imagined that the 'breach' if it should even be considered such, was quite minor; we would 'merely' ask people to account for the price they gave to goods rather than price the goods ourselves.

The following analysis will begin to explore what we can make of the naturally occurring order of price setting in everyday economic locations without a single price rule. The data derives from recorded interactions between us as sellers and potential buyers of objects we were selling. This data was transcribed and then coded by creating associations between discussions that shared common characteristics. The codes provided analytic themes through which to make sense of the data. We will begin with the Danish flea market and then proceed to the UK car boot sale. The subsequent discussion will reflect on some the features of order that provide a basis for comparing these locations and then we will consider the potential of this experimental method.

\section{Market experiments}

\section{Market 1: The flea market in Copenhagen}

Marta prepared for the Copenhagen experiment by booking a table at the Forum flea market. Sellers usually offer vintage jewellery, furniture, old books and vinyl records, antiquities and second-hand clothes. The Forum market is considered, by flea-market-goers and dedicated websites, Denmark's biggest and best, with up to 525 stalls. Marta was selling goods she had specially purchased at another flea market (in Hillerød, a town one hour from Copenhagen), combined with personal possessions she no longer wanted and objects from friends they no longer used. When customers came to Marta's stand, efforts were made for the experiment to engage them in a conversation. Fifty-two

9 Our initial foray into Silk Street came before this ethical imperative had been developed and some of the boot sale exchanges were too brief to inform participants of the experiment. 
customers' or potential customers' interactions were recorded on the first day, and 42 the second day. Due to space constraints, we will attend here to a narrow subset of interactions that focused most clearly on articulating the naturally occurring order of price setting at the flea market.

The gentle 'non-breach' experiment, whereby we would ask potential customers to account for their price setting, provoked an unexpected reaction among buyers. They walked away. They were not willing to talk and so we were even denied the opportunity to gain analytical purchase on the type of walking away they were doing. Eventually one potential customer refused to take part in the experiment, but did state that:

in Danish we have a way of saying, that it is the seller that has to settle the price and we negotiate.

Following eight more unsuccessful attempts to get potential customers to account for their price setting, Marta decided to amend the breach experiment. It seemed that constitutive expectancies around price might be so fundamental in the flea market that buyers could not countenance their absence. Marta noted at the time: "I decided to change strategy, reflecting on the fact that the reactions could have been a sort of complaint: somehow the unwritten rules were broken by not having prices, by not providing them the possibility to negotiate."

When Marta started to propose prices (even prices that were substantially higher than the amount she had paid for an object), customers became willing to enter into negotiations and even discuss price setting. Marta's own order of price setting went something like this: if it was an item she had purchased the previous week in Hillerød, then she would establish an initial price based loosely on its cost, but with an added margin "so people could feel they were negotiating"; if the object was not Marta's (but belonged to a friend) she would check other stands and what price was being offered for similar objects and would then propose a lower price, given that these were objects friends no longer wanted and "to encourage potential buyers to join in a conversation".

Once Marta had started setting prices, customers were not only happy to negotiate prices, they were also happy to articulate their constitutive expectancies regarding the naturally occurring order of the Forum flea market as the following excerpt demonstrates. Here a potential buyer is interested in a vase:

because it is in very good conditions, and ... overall has a good feature. It is a flea market, therefore people need to negotiate the price, and it is the rule of the game! If you would have said $20 \mathrm{kr}$, then I would have thought it is too cheap and it is not worth the purchase, if you would have said 100, I would have thought it is too expensive and I would have been annoyed by you and leave. And 
since it is a flea market, I need to take into consideration that I need to negotiate the price.

Nowhere is it written down that 20 kroner or 100 kroner is too low or too high a price to pay for this vase. There is no algorithmic device, no price list, no prior access requirements to be part of this negotiation (no training or qualification on price), no economic model set out, no variables to be controlled or manipulated, and there is no marketing. Yet the potential buyer is clear: at 20 kroner they would have walked away and at 100 kroner they would have walked away. The constitutive expectancies around the acceptability of a price banding (somewhere between 20 and 100) are absolute, but only available as a feature of the interaction within this setting.

How does this work? The potential buyer is clear in her account: what is too cheap and what is too expensive is accounted for by the indexing of the flea market and the need to negotiate. Pointing to these documents provides a basis for reflexively accomplishing the price banding (between 20 and 100 kroner) as a sensible matter-a price range that can be demonstrably accounted for as normal given the context that is being indexed. Despite the range of questions that this account could provoke (why this banding, where does this come from?), it accomplishes a congruence of relevances that acts as an etcetera clause. First, the congruence of relevances here involves accountably indexing that the buyer and seller are both members of this interaction in the flea market, the need for negotiation and the presence of a particular need to set the price of this particular vase. As Garfinkel suggests, the congruence of relevances is key to establishing the relation of undoubted correspondence between what seems to be taking place in an interaction and what does take place:

For the conduct of everyday affairs the person assumes, assumes the other person assumes as well, and assumes that as he [sic] assumes it of the other person, the other person assumes it of him, that a relationship of undoubted correspondence is the sanctioned relationship between the actual appearances of an object and the intended object that appears in a particular way. For the person conducting his everyday affairs, objects, for him as he expects for others, are as they appear to be. (1967: 56)

Second, in place of any possibility that questions could be asked as to why this price banding must be set in this way, comes the ultimate appeal to this congruence: the seller is called upon to recognise that what is relevant in this interaction is that the seller is selling the vase and the potential customer is buying it. Any other price banding or change to the price banding would destroy this congruence of relevances: the customer "would have been annoyed by you and leave". Although other questions could be asked, they ought not to be in order to get on with the matter to hand: setting a price for the vase. The relationship of undoubted correspondence is completed by this 
etcetera clause that cuts the possibility of further questioning and the price is set and the vase is sold.

Something similar can be seen in the following example, where the acceptability of the price is accountably accomplished as a basis for not needing further negotiation:

and they always start by bargaining half price. My wife is always saying: ask the price and offer half. But in my mind I have an idea of what is a good price, how much I am willing to spend. When you came up with the same price I was thinking, there was no point in bargaining

The "good price" here accountably accomplishes the congruence of relevances (that both buyer and seller are engaged in the exchange) and relationship of undoubted correspondence (that what appears to be going on-the sale-is what will come to pass). Negotiation is indexed here by pointing to the potential buyer's wife and her instructions on how to negotiate, whose warrant is negated by the buyer's own indexing of how much they are willing to spend. Not bargaining becomes a different kind of etcetera clause: it brings the interaction to a close through completion of the purchase.

A final example involves a potential buyer negotiating a price for two vintage milk bottles. Although the potential buyer begins at the same point as our preceding examples, pointing to price banding, he then dismisses other prices (in this case 37.5):

because I cannot go lower, I think 100 it is too much ... 50 is fine, 20 is too low. There are certain values that you expect to offer, you will never offer $37,5 \ldots$ and 50 was the right amount for me.

We can note here that 50 is not invoked as the correct price because it was the intrinsic value of the object, but because it was a number that accountably and demonstrably upheld (and thereby brought into being) the constitutive expectancies of the Forum flea market. To price an object at 37.5 or offer 37.5 as a customer would break these constitutive expectancies. The relationship of undoubted correspondence and the reflexive indexing of relevances still stand here, but the warrant for action-setting and paying a price-are also open to be negatively sanctioned. Once again there is no particular rule book that sets out the nature of these sanctions. Instead they are accomplished as a feature of the setting in which they take place and in turn act as a feature of that setting that can be further indexed.

Price setting at the Forum flea market was not about establishing a number that customers would pay, but establishing a starting point. This provided an entry into an interaction in which accountable turn taking would demonstrably establish the congruence of relevances and relationship of undoubted correspondence that tied together seller and buyer and reflexively accomplished the nature and rules of the setting. 
Although we began with an attempted breach, the absence of prices led to nothing more than customers walking away. At the same time, the presence of prices was insufficient on its own for price setting interactions to take place; customers suggested that if a price was too high or too low, outside a certain price banding, or too weird (such as $37.5)$, then that could also prevent price setting from taking place. What counted as the right price and the price that was paid was an accomplishment of the interaction of the setting, making available for analysis constitutive expectancies, warrants for action, the possibility of negative sanctioning, and the indexing of notable other people, times or places within the setting.

\section{Market 2: A UK car boot sale in Oxford}

Daniel continued the experiment on pricing at a car boot sale on the edge of Oxford. Car boot sales have become a popular weekend activity in the UK in the last few decades (see Gregson et al. 2013; Gregson and Rose 2000; Gregson and Crewe 1997). Sellers turn up, pay a flat fee and then sell a mix of old or new items. On this particular Sunday morning, Daniel arrived noting the cold weather (2 degrees) and the darkness of the car park where the sale took place. The location seemed a bit run-down, with basic graffiti on the walls, litter blowing about, faded signs, and a closed-up pub to one corner of the car park. Daniel had a car boot packed full of unwanted Christmas presents donated by various family members, toys his children no longer played with and materials left over from some recent building work. As Daniel entered the car park, he was approached by an organiser in a high visibility vest and directed to a spot. Daniel got out of the car and started to think about how to set up his stall. Daniel's experiment featured 40 interactions (not all of which led to sales).

Following on from the Forum flea market, we can note in the following excerpt that constitutive expectancies were once again part of the reflexive and accountable, naturally occurring order of the boot sale. What we can also note in the following successful sale of a radiator at the beginning of the boot sale, is the brief nature of each turn in interaction and also the importance of turn taking to establish the congruence of relevances-that the buyer and seller are recognisably tied to the shared activity of accomplishing a sale:

Man4: How much is the radiator?

Daniel: Hmmm. What would you think?

Man4: I don't know. You tell me.

[Pause]

Man4: This is the boot sale. You set the price and then I agree. 
Daniel: Well, I'm quite happy to get rid of it. It's really heavy.

Man4: It's a single radiator.

[Man4 spends several minutes looking over the radiator, lifting it up].

Man4: You have the valve?

[Pause]

Daniel: No.

Man4: $£ 1$ and I'll collect it later.

Daniel: $£ 2$.

Man4: You see. You set a price and it is all done in a second. That is the boot sale.

The shorter turns in interaction in comparison to the flea market seem to require a number of indexical comments. The boot sale is pointed towards twice ("this is the boot sale", "that is the boot sale") and the price setting three times ("You tell me", "You set the price", "You set a price"). In a short exchange this brings price setting and the boot sale together in a tight congruence of relevances that establishes a narrowly focused constitutive expectancy; there is nothing more or less than price to be focused on here. The potential buyer does not index anything outside the immediate interaction. Only the price and the object of price setting, the radiator, is focused on. We learn nothing of the buyer's life outside the exchange as nothing from outside the exchange is made demonstrably and accountably apparent by the buyer. Even the seller only points to the weight of the radiator as a nominally indexed 'outside' to the exchange, perhaps indicating that he does not wish to carry this heavy object home. To keep the interaction so tightly defined around these specific relevances and this quick turn taking without elaborate articulation requires the frequent and demonstrable use of an etcetera clause. At every turn further questions could be asked of the account offered (around price, the radiator, its weight, the valve); but "This is the boot sale" operates as the basis for closing down these questions. As an etcetera clause it works through the seller being called upon by the buyer to recognise the interaction in which they are both participating, the shared or congruent relevance of this interaction (to sell and to buy), that this requires the setting of a price and nothing more or less. 10

10 This rapidity of price setting is a point briefly alluded to by Gregson and Crewe (1997). 
Garfinkel suggested that this method that members use to make sense of an interaction by utilising the documentary method as a means to continually make apparent the type of interaction in which members are engaged, does not involve members putting one instance of an interaction into a scientific corpus or classification. Instead instances of interaction involve "continually 'membershipping' it" (1967: 94). That is, the sense of the type of interaction in which members are engaged needs to be continually made apparent and agreed by the participants such that the type to which the interaction is a member is continually constituted. The tightly delimited congruence of relevances does this membershipping work here, continually ensuring that the interaction is oriented towards buying and selling and accomplishing the relation of undoubted correspondence-that what appears to be taking place is what takes place.

The rapid settlement of price through rapid turn taking exchanges was a regularly recurring feature of the naturally occurring order of the Oxford car boot sale. The following exchange typifies many of these features of the rapid price settlement:

Woman1: Hi. It's cold isn't it. How much is the rug?

Daniel: Well, what do you think it's worth?

Woman1: I don't know

Daniel: [presenting the rug by waving his hand across it like a salesman] It's not been used much

Woman1: OK $£ 5$ ?

Daniel: $\mathrm{Mmmm}$

Woman1: £7?

Daniel: Oh OK.

The potential buyer offers an indexical introduction (bringing the weather into the interaction) but also identifies the item of interest and makes an inquiry into how much it costs in ten words. What might otherwise be a long preamble to negotiation is foreshortened. Both parties pay recognition to this first turn, that the weather is nothing more than an opening gambit, by not referring to it again. It is an opening that simultaneously closes off its own relevance by pointing to the rug as the true focus of interest. That the seller also orients the next turn in interaction to the rug establishes this sense for the interaction. Once again the interaction is membershipped as an occasion for buying and selling. The weather is now finished as a topic. Daniel introduces part of the terms of the experiment ("what do you think it's 
worth") and the customer responds with a brief counter to put the emphasis on price setting back on to the seller. "I don't know" here connotes within the interaction both that the potential buyer will not offer a price, but is also not responsible for the offering of prices. To continue the experiment is somewhat difficult here; the potential buyer is reasserting a constitutive expectancy that they assume is also held by the seller, that this is the seller's object for which they ought to set a price. The moral warrant for price setting is then shifted back onto the potential buyer by the seller through the somewhat jokey waving of a hand across the rug, indexing the stereotypical behaviour of sales people perhaps seen in films, but also with the turn "It's not been used much". Although this turn is not subsequently taken up in successive turns in the interaction and so might be said to be of trivial importance in the setting of the price, it does shift the moral warrant for price setting back on to the potential buyer. The importance of the actual preceding usage of the rug, is negligible. What is important is the work of not setting a price, shifting the moral warrant for action back on to the potential buyer. The "OK" here can be heard as a resigned acceptance of the price setting role that the potential buyer must now take up, followed by " $£ 5$ ?" as a means to both affirm that she has taken on this role and will execute the warrant she holds.

The "Mmm" is then an inconcludable pause in the price setting. It poses a question with regard to its interactional purpose, but offers no etcetera clause that might close down future questions or move the interaction towards its conclusion. " $£ 7$ ?" then operates to give the "Mmm" a specific sense. That the offer for the rug has been increased now indexes the "Mmm" as a call for the potential buyer to up her price. The surprised "Oh OK" completes the sale and sets the price, accepting $£ 7$ as the amount that will be paid. But the surprised tone also suggests that the "Mmm" may not have been a bargaining move at all. It may have been a more straightforward pause. That such pauses cannot be taken by participants as anything other than a move in price setting further emphasises the importance of the congruence of relevances and constitutive expectancies of the car boot sale; that each expects the turns in interaction to be price focused and expects the same of the other participants in the interaction and expects that they expect the same of them. It also points to a feature of agreements that Garfinkel was interested in. According to Garfinkel an agreement is not an actuarial device to predict each other's future activities. Instead an agreement enables participants "to normalize whatever their actual activities turn out to be" (1967: 74). In the preceding exchange, the "Mmm" and the " $£ 7$ ?" accomplish this sense of what it is that the participants are agreeing. It is the activities that set what the agreement was.

The congruence of relevances, constitutive expectancies, the holding and shifting of moral warrants, the rapid turn taking, and the 
inescapability of price setting are what constitute the naturally occurring order of price setting at the boot sale. This rapidity of turn taking and price settlement features again and again in our interactions. In the following exchange, a product is selected and a price enquired in the same move. Unlike the preceding excerpt there is no opening gambit about the weather and the customer does not even bother to name the item she is interested in. Instead the turns move the conversation rapidly towards price setting. The potential buyer is not fazed by the absence of a price and is quick to make an offer. While Daniel's turn " $£ 2.50$ ?" could be heard as an invitation to extend the exchange and return with a counter-offer, instead the potential buyer accepts the price ("OK") and the exchange is completed:

\footnotetext{
Woman4: How much? [picking up a plastic animal toy]

Daniel: That's more than [Daniel gestures towards another customer whom Woman4 witnessed buying several toys].

Woman4: Yes I can see that. How much?

Daniel: What do you think? Make an offer of what you think it's worth?
}

Woman4: $£ 2$ ?

Daniel: $£ 2.50$ ?

Woman4: OK [she pays with the correct money and quickly departs]

Rapid price setting at the boot sale was characterised by a number of routine practices for reaching agreement. Along with the preceding example in which the first counter offer is accepted, came instances where buyer and seller would "meet in the middle" between first offer and first counter offer, or potential buyers would stick to their first offer and a price would be set. Constitutive expectancies and the congruence of relevances were made accountably and demonstrably part of the interaction in each occasion of the use of routine practices of price setting. The seller was called to account by the buyer to recognise that what they were engaged in was a routine means to achieve their shared purpose: to set a price. One final means of rapid price setting involved potential buyers reassuring the seller that their offer was a sanction-able feature of the exchange:

[A couple approach the stall. Woman21 and Man9. Woman21 picks up a flower pot]

Woman21: Pot?

Daniel: What do you think? 
Woman21: 20p.

Daniel: Really?

Woman21: Yes. It's OK.

Daniel: OK.

[Woman21 picks up two pots and hands over 40p smiling].

The turn in this interaction "Yes. It's OK" does much of the work in setting the price here. It closes down the possibility of further questions and asserts the moral warrant of the potential buyer: she will set the price and establish her warrant for setting the price. The "OK" in response in the next turn in the interaction accountably and demonstrably accepts that the potential buyer holds this warrant and that the price can indeed be set at 20p. Picking up two pots and handing over 40p returns us to Garfinkel's previous suggestion that an agreement is the basis for normalizing whatever turns out to be the action in which the participants are involved.

\section{Discussion and conclusion}

In recent years scholars have begun to conceive of experimentalising economic phenomena (Wherry 2014; Muniesa 2016a, 2016b) not through the confines of economic experiments, but through qualitatively rethinking what it means to be economic. Our breach experiments offer one practical means to begin experimental engagement with economic phenomenon in this paper price setting. We were interested in settings without an institutionalised single price rule, with few barriers to entry, where little in the way of rules, prior training or other formal processes were required for participation. We wanted to see how a regularly repeated, naturally occurring order to price setting could characterise these everyday economic locations even in the absence of formal, written rules or complex access requirements.

Our experiments drew on Garfinkel's $(1963,1967)$ work to try and make sense of the interactions that took place. We noted that the means by which price setting took place could be described through what Garfinkel termed the constitutive expectancies made available in turns in interactions, to be held to account by other participants in interaction through their subsequent turns. This is not to say that the constitutive expectancies exist in any straightforward manner prior to the interaction. They are constituted within the interaction and constitutive of the sense of the interaction. We further explored how these constitutive expectancies build a congruence of relevances-the constitution of a set of interactionally agreed upon terms for the interaction that would orient the interaction as the interaction 
unfolded. We also looked to make sense of these interactions in line with ethnomethodological suggestions that sense making involves the ongoing reflexive accomplishment of members of the interaction, indexing or pointing to various features to be made to make sense and agreed upon in the interaction. The in-principle inconcludability of turns in interactions - that each account offered could be the subject of further questioning-was notable through the deployment of various etcetera clauses that were used to close down the possibility of questions. We suggested that this activity could be considered as the basis for accomplishing a relation of undoubted correspondence between what appeared to be taking place and what did take place.

Exploring the results of our breach experiments through these ethnomethodological precepts was useful insofar as it helped point up some key differences in the way price setting occurred in each location. Although both the Forum flea market and the Oxford car boot sale had very low entry requirements, no written rules on price setting and very few formal restrictions, they each exhibited different naturally occurring orders of price setting. In the flea market, prices were crucial. Our initial conception of the breach experiment proved nothing more than the importance of constitutive expectancies around the presence of price. Having a price did not set the price that would be paid for a good, but having no price meant that no conversation would take place. Once prices were attached to goods, conversations followed if the price was deemed to be within an appropriate band. Appropriateness here was accomplished through the indexing of the immediate context. The flea market was used to establish pricing appropriateness. In these interactions a broad array of indexical expressions (from partner's expectations to the history of objects) were made accountably and demonstrably available in interactions as the basis for orienting price setting. A congruence of relevances was established in these exchanges-that the potential buyer was here to buy and expected the seller to be there to sell and expected the seller to hold the same expectations of the buyer. The expectation was that what was relevant for one was congruent with what was relevant for the other. The broad array of indexical expressions used in the flea market then became the quite articulate basis for establishing this congruence and the price to be paid.

Such indexicality was also prevalent in our initial example in Silk Street. A broad variety of other people, places, prices and products were indexed here, but unlike the flea market such indexing took place within interactions that were more physical (with sellers pulling buyers to one side) and staccato in their rhythm (with buyers walking away and coming back several times before a purchase). In Silk Street the congruence of relevances was ensured by this physicality-that the potential buyer could recognise that they were being taken aside in 
order to set out the special terms for a deal to which only they and the seller were privileged.

Although we can also note constitutive expectancies and the congruence of relevances in the Oxford car boot sale, these took a distinct form. Rapid exchanges constituted expectancies for buyers and sellers, but without the physicality of Silk Street or the more articulate accounts of the Forum flea market. Through rapid back and forth exchanges, the moral warrant for price setting-who was accountably and demonstrably in the position to set the price-shifted between potential buyer and seller. To maintain the breach experiment was also difficult here, but for different reasons. It was not that the absence of a price foreshortened interactions, but that potential buyers frequently shifted the moral warrant for price setting back to the buyer. This seemed to be a key constitutive expectancy made available and made to make sense within the boot sale interactions. In comparison to the flea market and to Silk Street, exchanges at the boot sale contained far fewer expressions that indexed contexts beyond the boot sale. It seemed unusual for potential buyers to point to anything outside the exchange as the basis for price setting. The rapid exchanges and absence of indexical expressions gave the impression that the boot sale was all about price and accomplishing a price rapidly.

The experiments proved to have analytic utility in bringing these gently structured comparisons to the fore. The experiments provided us with the opportunity to engage with the basis for price setting in different everyday economic locations. We also felt that this was the opening to a mode of research that has future potential. First we found the method liberating as a means to engage in depth with the rich details of everyday price setting, while also producing a comparison that did not depend on the same kinds of constraints as, for example, laboratory economic experimentation. Although we drew inspiration from Garfinkel's $(1963,1967)$ breach experiments, we also developed our own kinds of breach and tried to address noted ethical concerns by ensuring people were aware of the experiments as far as possible. For us this suggests that our relatively small-scale, qualitative experimental experiments might have a future. It could be used to try and uncover more details on the naturally occurring order of price setting in other locations. Second, although we drew inspiration from recent science and technology studies (STS) scholarship on economic phenomena (Hagberg and Kjellberg 2014; Lepinay and Callon 2009; Karpik 2010; Cochoy and Grandclément 2005; Beunza et al. 2006; Muniesa 2007; Caliskan 2007), there has not been the space within the confines of this primarily empirical paper to draw out further comparisons or connections with this literature. It seems to us that thinking more about ways to experimentalise economic activities beyond the narrow scope of our project reported on here could provide new grounds for 
asking questions of finance, other forms of price setting, market activity and accounts. This paper is no more than a start.

Acknowledgment. This research was supported by the European Research Council under grant no. 313173.

\section{References}

Aspers, Patrick. 2011. Markets (Vol. 1). Cambridge: Polity Press

Beckert, Jens. 2011. "Where Do Prices Come From? Sociological Approaches to Price Formation." Socio-Economic Review 9(4): 757-86.

Beunza, Daniel, Iain Hardie, and Donald MacKenzie. 2006. "A Price is a Social Thing: Towards a Material Sociology of Arbitrage." Organization Studies 27(5): 721-745.

Bourdieu, Pierre. 1984. Distinction: A Social Critique of the Judgment of Taste (La distinction: critique social du jugement), Minuit. Richard Nice (trans.). Cambridge, MA: Harvard University.

Caliskan, Koray. 2007. "Price as a Market Device: Cotton Trading in Izmir Mercantile Exchange.” The Sociological Review 55(2): 241-260.

Cochoy, Franck. 2008. "Calculation, Qualculation, Calqulation: Shopping Cart Arithmetic, Equipped Cognition and the Clustered Consumer." Marketing Theory 8(1): 15-44.

Cochoy, Franck, and Catherine Grandclément. 2005. Publicizing Goldilocks' Choice at the Supermarket: The Political Work of Shopping Packs, Carts and Talk. Cambridge, MA: MIT Press

Csikszentmihalyi, Mihaly, and Eugene Halton. 1981. The Meaning of Things: Domestic Symbols and the Self. Cambridge: Cambridge University Press.

Finch, John, Susi Geiger, and Rachel Harkness. 2016. "Marketing and Compromising for Sustainability: Green Chemistry, Regulation and Competing Orders of Worth in the North Atlantic.” Marketing Theory 17(1): 71-93.

Fourcade, Marianne. 2010. "The Problem of Embodiment in the Sociology of Knowledge: Afterword to the Special Issue on Knowledge in Practice." Qualitative Sociology 33(4): 569-574.

Garfinkel, Harold. 1963. "A Conception of and Experiments with 'Trust' as a Condition of Concerted Stable Actions." In The Production of Reality: Essays and Readings on Social Interaction, edited by Oswald Harvey, 381-392. New York: Ronald Press. Company.

- 1967. Studies in Ethnomethodology. New York: Englewood Cliffs.

Giesler, Markus. 2008. "Conflict and Compromise: Drama in Marketplace Evolution." Journal of Consumer Research 34(6): 739-753.

—. 2012. "How Doppelgänger Brand Images Influence the Market Creation Process: Longitudinal Insights from the Rise of Botox Cosmetic." Journal of Marketing 76(6): 55-68. 
Gregson, Nicky, and Louise Crewe. 1997. "Performance and Possession: Rethinking the Act of Purchase in the Light of the Car Boot Sale." Journal of Material Culture 2(2): 241-63.

Gregson, Nicky, and Gillian Rose. 2000. "Taking Butler Elsewhere: Performativities, Spatialities and Subjectivities.” Environment and Planning D: Society and Space 18: 433-452.

Gregson, Nicola, M. Crang, J. Laws, T. Fleetwood, and H. Holmes. 2013. "Moving Up the Waste Hierarchy." Resources, Conservation and Recycling 77: 97-107.

Guala, Francisco. 2008 "How to do Things with Experimental Economics." In Do Economists Make Markets? On the Performativity of Economics, edited by Donald MacKenzie, Fabian Muniesa, and Lucia Siu, 128-162. New York: Princeton University Press.

Hagberg, Johan, and Hans Kjellberg. 2014. "How Much Is It? Price Representation Practices in Retail Markets." Marketing Theory 15(2): 179-199.

Hennion, Antoine. 2004. "Pragmatics of Taste." In the Blackwell Companion to the Sociology of Culture, edited by Mark Jcobs and Nancy Weiss, 131144. Malden, MA: Blackwell.

Humphreys, Ashlee. 2010. "Megamarketing: The Creation of Markets as a Social Process." Journal of Marketing 74(2): 1-19.

Karpik, Lucien. 2010. Valuing the Unique: The Economics of Singularities. Princeton, NJ: Princeton University Press.

Kotler, Philip. 1972. Marketing Management. Delhi: Pearson Education.

Lepinay, Vincent, and Michel Callon. 2009. "Sketch of Derivations in Wall Street and Atlantic Africa." In Accounting, Organizations, and Institutions: Essays in Honour of Anthony Hopwood, edited by Christopher Chapman, David Cooper, and Peter Miller, 259-289. Oxford: Oxford University Press.

Livingston, Eric. 2006. “The Context of Proving." Social Studies of Science 36(1): 39-68.

Lynch, Michael. 2000. "Against Reflexivity as an Academic Virtue and Source of Privileged Knowledge." Theory, Culture and Society 17(3): 26-54.

MacKenzie, Donald. 2002. "The Imagined Market." London Review of Books 24(21): 22-24.

Miller, Ross. 2002. Paving Wall Street: Experimental Economics and the Quest for the Perfect Market. New York: John Wiley \& Sons.

Muniesa, Fabian. 2007. "Market Technologies and the Pragmatics of Prices." Economy and Society 36(3): 377-395.

- 2014. The Provoked Economy. London: Routledge.

—. 2016a. "Setting the Habit of Capitalization: The Pedagogy of Earning Power at the Harvard Business School, 1920-1940.” Historical Social Research 41(2): 196-217.

- 2016b. "The Problem with Economics: Naturalism, Critique and Performativity." In Enacting Dismal Science: New Perspectives on the 
Performativity of Economics, edited by Ivan Boldyrev, and Ekaterina Svetlova. London: Palgrave Macmillan. pp 109-29.

Muniesa, Fabian, and Michel Callon. 2008. "Economic Experiments and the Construction of Markets." In Do Economists Make Markets? On the Performativity Of Economics, edited by Donald MacKenzie, Fabian Muniesa, and Lucia Siu, 163-189. Princeton, NJ: Princeton University Press.

Pine, Joseph, and James Gilmore. 1999. The Experience Economy: Work Is Theatre and Every Business a Stage. Boston, MA: Harvard Business School Press.

Scaraboto, Daiane, and Eileen Fischer. 2013. "Frustrated Fatshionistas: An Institutional Theory Perspective on Consumer Quests for Greater Choice in Mainstream Markets." Journal of Consumer Research, 39(6): 12341257.

Simmel, Georg. 2004. The Philosophy of Money, 3rd edn, New York: Routledge.

Smith, Charles. 1990. Auctions. The Social Construction of Value. Los Angeles, CA: University of California Press.

Smith, Vernon. 1962. "An Experimental Study of Competitive Market Behaviour." Journal of Political Economy 70: 111-137.

- 2000. Bargaining and Market Behavior: Essays in Experimental Economics. Cambridge: Cambridge University Press.

Stark, David. 2009. The Sense of Dissonance: Accounts of Worth in Economic Life. Princeton, NJ: Princeton University Press.

Tversky, Amos, and Daniel Kahneman. 1986. "Rational Choice and Framing of Decisions." Journal of Business 59: 252-278.

Veblen, Thorstein. 1899. The Theory of the Leisure Class. New York: Modern Library [2001].

Wherry, Fred. 2014. "Analyzing the Culture of Markets." Theory and Society 43(3-4): 421-436.

Zeithaml, Valarie. 1988. "Consumer Perception of Price, Quality and Value." Journal of Marketing 52(3): 2-22.

Zelizer, Viviana. 1981. "The Price and Value of Children: The Case of Children's Insurance.” American Journal of Sociology 86(5, Mar): 10361056. 
Daniel Neyland is Professor at Goldsmiths Sociology Department. His research engages with issues of governance, accountability and ethics in forms of science, technology and organisation. Drawing on ideas from ethnomethodology, science and technology studies (in particular forms of radical and reflexive scepticism, constructivism, actornetwork theory and the recent science and technology studies turn to markets and other forms of organising), his research is ethnographic in orientation. In particular he is interested in the question of how entities (objects, values, relationships, processes and also people) become of the world.

Marta Gasparin is a lecturer in innovation and design management at the University of Leicester. Her research explores how design and innovation emerges, how value is created, and the role of actors (objects, managers, designers) in the innovation and design process. She draws on ideas from science and technology studies and actornetwork theory. She is interested in design theory and the epistemological dimension of innovation, in particular the relation between design and art, design and aesthetics, design and epistemology, design and technology.

Lucia Siu was the co-editor of Do Economists Make Markets? On the Performativity of Economics. Her PhD thesis was on the commodity futures markets of China, and her MSc dissertation was on Hong Kong's dotcom bubble. She holds a $\mathrm{PhD}$ in Sociology from the University of Edinburgh. 